\title{
TYMPANOPLASTY USING PEDICLE TEMPORALIS FASCIA GRAFT- A NOVEL MODIFICATION OF UNDERLAY TECHNIQUE
}

\author{
Nalakath Kunjhimon Bashir1, Suma Radhakrishnan², Girish Raj ${ }^{3}$ \\ 1 Professor, Department of ENT, MES Medical College, Perinthalmanna, Kerala. \\ ${ }^{2}$ Additional Professor, Department of ENT, Government Medical College, Calicut. \\ 3Professor, Department of ENT, MES Medical College, Perinthalmanna, Kerala.
}

\begin{abstract}
BACKGROUND

Temporalis fascia is the most commonly used graft material for tympanoplasty with closure of the perforation of $70 \%$ to $90 \%$ of cases. We propose a novel modification of inlay surgical technique, pedicle temporalis fascia graft, to improve the graft take-up rate without compromising the hearing results

Aim- The purpose of this study is to assess the take-up rate and hearing results of type 1 tympanoplasty using pedicle temporalis fascia graft.
\end{abstract}

\section{MATERIALS AND METHODS}

This is a retrospective study conducted from 01/06/2013 to 30/09/2015. 43 patients with safe central perforations, who underwent type 1 underlay tympanoplasty using a pedicle temporalis fascia graft were studied. The outcome measurements were graft take-up rate and audiometric results.

\section{RESULTS}

Graft take-up rate in this study was $97.4 \%$ and hearing improvement was about $90 \%$. Graft take-up rate is comparable with the best results achieved by any other technique and hearing improvement is at par with most of the studies.

\section{CONCLUSION}

Our modification of type 1 tympanoplasty using a pedicle temporalis fascia graft gives excellent graft take-up rate. This technique needs refinement, and we strongly recommend trying this in difficult cases and in revision tympanoplasties.

\section{KEYWORDS}

Tympanoplasty, Medial Graft, Lateral Graft, Pedicle Graft.

HOW TO CITE THIS ARTICLE: Bashir NK, Radhakrishnan S, Raj G. Tympanoplasty using pedicle temporalis fascia graft- A novel modification of underlay technique. J. Evolution Med. Dent. Sci. 2017;6(30):2428-2431, DOI: 10.14260/Jemds/2017/524

\begin{abstract}
BACKGROUND
Surgery for chronic otitis media is one of the commonest otologic procedures performed in developing countries. Since the inception of tympanoplasty by Wullstein in 1952, a large variety of graft materials and different surgical techniques have been tried with varying results. In contrast to all graft materials, temporalis fascia has several advantages including physiological compatibility with tympanic membrane. In middle ear surgery, we are often looking for graft take-up rate and hearing improvement as outcome measures of success. Graft take-up means the anatomical position and total epithelialisation of the healed tympanic membrane after surgical intervention. There are two distinctly different methods of placement of the graft namely underlay and overlay.
\end{abstract}

Financial or Other, Competing Interest: None.

Submission 11-01-2017, Peer Review 30-03-2017,

Acceptance 06-04-2017, Published 13-04-2017.

Corresponding Author:

Dr. Nalakath Kunjhimon Bashir,

Professor of ENT,

MES Medical College, Palachode,

Perinthalmanna-679338, Kerala.

E-mail: bashirnk@gmail.com

DOI: $10.14260 /$ jemds $/ 2017 / 524$

\section{(c) $(7)$}

Underlay and overlay techniques refer to the placement of the graft either medial or lateral to the fibrous layer of the tympanic membrane (TM) remnant, first described by House[1] and Shea, ${ }^{[2]}$ respectively. The underlay technique, the most common and easiest technique, is typically used for posterior perforations, whereas the overlay technique is more technically challenging and particularly suited for large or anterior perforations.[3] The most accepted and frequently used technique is underlay of temporalis fascia.[4]

The underlay technique could be performed through post-auricular, end aural or transcanal approach. Even though general anaesthesia is preferred, all these procedures can be done under local anaesthesia as well. Temporalis fascia is the most commonly used graft material with closure of the perforation of $70 \%$ to $90 \%$ in different hands. However, in some situations such as advanced middle ear pathology, retraction pockets, and atelectatic ears, temporalis fascia tends to undergo atrophy in the subsequent postoperative period regardless of placement techniques.[5]

Different surgical techniques have been tried to improve the graft take-up rate, as well as to improve the hearing results. Graft take-up rate can be improved by using certain materials but at the expense of less acceptable hearing results, for example cartilage tympanoplasty. Vibratory pattern of the tympanic membrane is mechanically reduced by cartilage, contributing to some impairment in functional results, especially in the higher tones.[6] Conceptually, the 
thinner grafting material provides better vibration and transmission of sound.[4] The relentless effort by the pioneers in the field, the graft take-up rate has been improved remarkably. Presently, with reasonable surgical skill and prudent case selection, most of us are able to achieve a takeup rate above $90 \%$. In spite of the very good results, we are compelled to face occasional failures. Failures are like residual perforation, re-perforation and necrosis of the total graft material.

PM Shenoy in 1982 showed with electron microscopy that physiological heat on the collagen matrix seems at first, to produce generalised swelling of the fibres, the denatured protein is drawn into dome shaped structures with circular defects like craters.

After placement of dry temporalis fascia, it gets rehydrated after surgery. After rehydration, significant shrinkage has been demonstrated by England RJ et al. It is therefore proposed that a cause of increased failure rates, particularly in anterior perforations, is due to graft rehydration and shrinkage. [7]

In general, the human race has always been striving hard for excellence. As any other scientifically oriented person our duty is to try to find out methods to improve the graft take-up rate further without jeopardising the hearing results. In accordance with that we propose a new surgical technique to improve the graft take-up rate without compromising the hearing results.

\section{MATERIALS AND METHODS}

This retrospective study of type 1 pedicle temporalis fascia graft tympanoplasties was performed by the author in Government Medical College, Thiruvananthapuram and Kozhikode, tertiary care centres in Kerala, South India from $01 / 06 / 2013$ to 30/9/2015. Total number of patients studied were 43 , out of which 18 were male and 25 were female, age ranged from 18 to 55 years. Patients who underwent type 1 tympanoplasty using pedicle temporalis fascia graft only included in this study. Cases with ossicular chain erosion, retraction pockets, cholesteatoma were excluded from the study. Those who failed to come for followup for at least three months were also excluded. A detailed clinical history and examination was done in all patients. Hearing was assessed by tuning fork tests and pure tone audiogram. In all patients, otomicroscopy, pre-operative and post-operative audiograms were performed.

All patients were operated under local anaesthesia and through post-aural approach. After local infiltration, subcutaneous soft tissue is elevated from the temporalis fascia through the post-aural incision. An adequate size temporalis fascia is marked on the external surface of the temporalis fascia and the fascia is incised accordingly. The incision [Figure 1] is made in such a way that the anterior, superior and posterior part of the fascia is incised but the inferior aspect is left free.

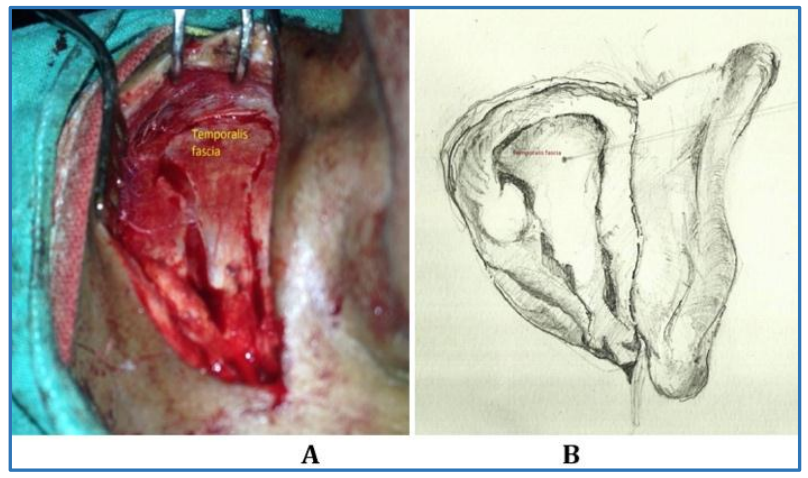

Figure 1 a \& b. Incision over the Temporalis Fascia extending to Periosteum

Now the temporalis fascia is carefully elevated off the temporalis muscle in an inferior direction. When the dissection reaches the attachment of the temporalis fascia to the temporal line anterior and posterior aspect of the incision on the fascia is extended inferiorly to the periosteal lining of the mastoid cortex. Elevation of the temporalis fascia is continued inferiorly in continuity with the periosteum up to the mastoid tip. Now the temporalis fascia graft with attached periosteum is completely free except its attachment to the mastoid tip as a pedicle [Figure 2]. During further surgical procedure the temporalis fascia graft is kept away from the surgical field by wrapping it in a moistened gauze piece.

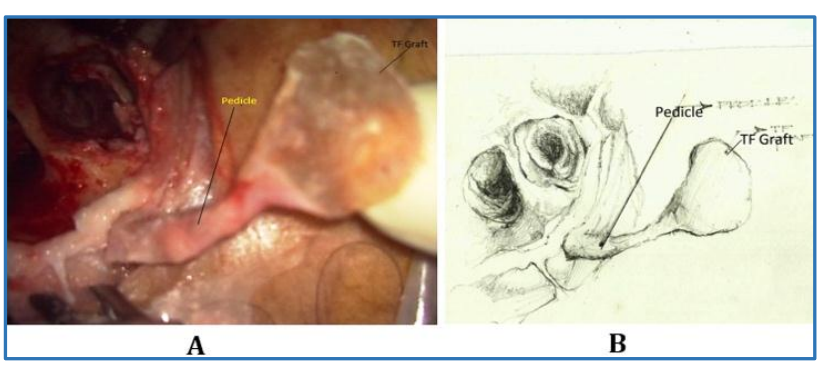

Figure 2 a \& b. TFG Elevated with an Attached Pedicle

The operative procedure is continued as usual underlay tympanoplasty. Edges of the perforation in the pars tensa is freshened with a sickle knife and posterior tympanomeatal flap is elevated after making an incision at $1 \mathrm{o}^{\prime}$ clock - 5 o'clock position. Annulus is lifted off its groove and the handle of malleus is denuded off all the remaining squamous epithelium attached to it. The temporalis fascia graft is manipulated and placed under the tympanomeatal flap and over the handle of malleus covering the whole perforation [Figure 3]. Tympanomeatal flap is repositioned, external auditory canal is packed with gel foam and the wound is closed in layers.

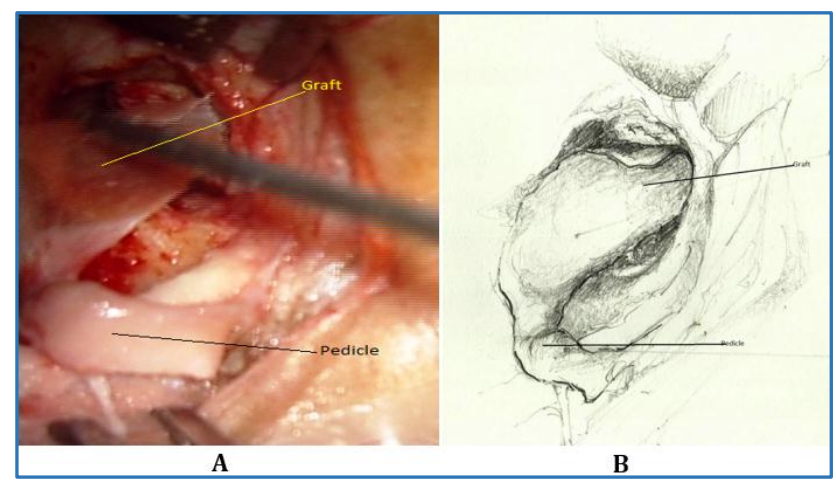

Figure 3 a \& b. Temporalis Fascia Graft is Manipulated 


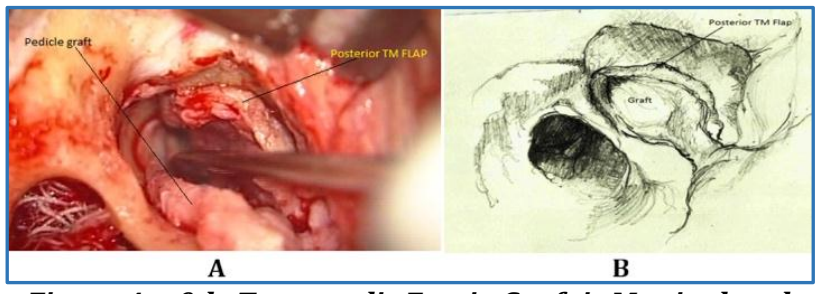

Figure 4 a \& b. Temporalis Fascia Graft is Manipulated

\section{Followup}

Patients were discharged after 24 hours observation with prophylactic antibiotics, analgesics and antihistamines. Patients were called back after one week for suture removal. Next followup was after 2 weeks for the removal ear pack, no suction clearance was done and eardrops were prescribed only if the gel foam is remaining in the external canal or the canal is wet. All patients were followed up monthly for the next two months and a pure tone audiogram was done at the end of three months. An otomicroscopy was also done during this visit to assess the graft take-up. Otomicroscopy was repeated at an interval of three months for the next one year.

\section{RESULTS}

Graft Take-up rate is defined as well epithelialised tympanic membrane in the normal anatomic position without any retractions, having normal conductive characteristics, and normal mobility. Air-bone gap [ABG] is defined as the mean of ABGs at frequencies 500, 1000 and $2000 \mathrm{~Hz}$ and ABG less than $10 \mathrm{~dB}$ is taken as normal.

Out of the 43 patients only one patient developed a perforation 2 months after the surgery following an acute middle ear infection. In rest of the 42 patients graft take-up was complete and the tympanic membrane was well epithelialised. So graft take-up rate is $97.67 \%$.

\begin{tabular}{|c|c|c|}
\hline Total Patients & Success & Failure \\
\hline 43 & $42[97.7 \%]$ & $1[2.3 \%]$ \\
\hline \multicolumn{3}{|c|}{ Table 1. Graft Take-up Rate } \\
\hline
\end{tabular}

ABG closure less than $20 \mathrm{~dB}$ is obtained in over $90 \%$ of cases. After the surgical intervention, hearing improved to the normal level in 30 patients out of the total number of 43 . Details of the pre-operative hearing loss and post-operative ABG closure are given in Table no: 2 .

\begin{tabular}{|c|c|c|c|c|}
\hline $\begin{array}{c}\text { Pre-op } \\
\text { ABG }\end{array}$ & $\begin{array}{c}\mathbf{0} \text { to } 10 \\
\mathbf{d B}\end{array}$ & $\begin{array}{c}\mathbf{1 0} \text { to } \mathbf{2 0} \\
\mathbf{d B}\end{array}$ & $\mathbf{2 0}$ to $\mathbf{3 0} \mathbf{~ d B}$ & $\begin{array}{c}\mathbf{3 0} \text { to } 45 \\
\mathbf{d B}\end{array}$ \\
\hline $\begin{array}{c}\text { Number of } \\
\text { patients }\end{array}$ & 0 & $9[20.9 \%]$ & $29[67.4 \%]$ & $5[11.6 \%]$ \\
\hline $\begin{array}{c}\text { Post-op } \\
\text { ABG }\end{array}$ & 0 to $10 \mathrm{~dB}$ & 10 to $20 \mathrm{~dB}$ & 20 to $30 \mathrm{~dB}$ & 30 to $45 \mathrm{~dB}$ \\
\hline $\begin{array}{c}\text { Number of } \\
\text { patients }\end{array}$ & $28[65.1 \%]$ & $8[18.6 \%]$ & $6[14 \%]$ & $1[2.3 \%]$ \\
\hline \multicolumn{5}{|c|}{ Table 2. Hearing Results } \\
\hline
\end{tabular}

\section{DISCUSSION}

Over the years, several surgical techniques have been tried to improve the take-up rate and hearing results such as underlay, overlay, cartilage tympanoplasty,[5] Anterior tucking [anterior hitch],[8] over-under technique,[9,10] vein graft,[2] mediolateral tympanoplasty,[11] sandwich graft tympanoplasty,[12] modified window shade by Schraff et al,[13] paper patching, lobule fat graft, etc. We are presenting a modification of over-under tympanoplasty using a pedicle temporalis fascia graft to improve the graft take-up rate without jeopardising the hearing results.

One of the reasons for graft failure in tympanoplasty using temporalis fascia graft is graft necrosis.[7] Various studies have shown that graft take-up rate is more when we use cartilage graft instead of temporalis fascia. The only positive aspect of cartilage graft is that it stays longer in the middle ear without necrosis than temporalis fascia. In all other aspects cartilage is inferior to temporalis fascia graft as a graft material for tympanoplasty. From these observations one can, with reasonable certainty, presume that graft takeup rate is better when the graft material stays longer in the middle ear. Pedicle graft resists necrosis more than a free graft. That is the rationale behind this study. The results of our study support our hypothesis; graft take-up rate in our study is $97.7 \%$. And we hope that with more experience and refinement of this technique, we can further improve the results.

The overall take-up rate of tympanoplasty using temporalis fascia graft in various studies ranges from 78\% [14] to $97.4 \% \cdot{ }^{[9]}$ And hearing improvement varies from $70 \%{ }^{[11]}$ to $85.7 \% .[15]$

Nardone $\mathrm{M}$ et al reported $78 \%$ success rate in a critical analysis of long-term results in a 1,000-adult patient series. And Stage J et al claimed $97.4 \%$ success rate in underlay tympanoplasty with graft placed over the handle of malleus.

The success rate in mediolateral tympanoplasty was $97 \%$ and hearing improvement in $70 \%$ of the operated ears as reported by Jung TTK and Park SK.[11] Palisade cartilage tympanoplasty obtained $71.43 \%$ success and average postop ABG was $10.73 \pm 7.90$ as reported by Marko Velepic.[16]

Hai Gavreil et al reported $92.3 \%$ graft take-up rate and average hearing improvement of $15 \mathrm{~dB}$ by their novel inferior flap technique. The graft take-up rate of window shade grafting technique was $94 \%$ and hearing improvement was $85.7 \%$, reported by Dr. Ninad S Gaekwad et al.

The preliminary results of this novel modification of tympanoplasty using a pedicle temporalis fascia graft have been comparable with the best results achieved with tympanoplasty by any other technique as far as the graft take-up rate is concerned. ABG closure achieved in this study is less than $20 \mathrm{~dB}$ in $83.7 \%$ which is also comparable with most of the studies.

Graft resorption is one of the reasons for failure of temporalis fascia graft. Since we have been using a pedicle temporalis fascia graft the possibility of resorption is remote as it derives its nutrition through the pedicle, probably, that may be the reason for a higher take-up rate achieved by this technique.

The external auditory canal becomes narrower after the surgery due to extra space occupied by the pedicle under the tympanomeatal flap which is one drawback of this technique. This could be minimised by doing a canalplasty in our later cases.

\section{CONCLUSION}

Our modification of type 1 tympanoplasty using a pedicle temporalis fascia graft gives excellent graft take-up rate. The functional results achieved by this technique are also comparable with the published data. Highlight of this 
technique is the use of a pedicle graft instead of a free temporalis fascia graft.

\section{REFERENCES}

[1] House WF. Myringoplasty. Arch Otolaryngol 1960;71:399-404.

[2] Shea JJ. Vein graft closure of eardrum perforations. J Laryngol Otol 1960;74:358-62.

[3] Gersdorff M, Gerard JM, Thill MP. Overlay versus underlay tympanoplasty. Comparative study of 122 cases. Rev Laryngol Otol Rhinol 2003;124(1):15-22.

[4] Wen-Hung W, Yen-Chun L. Minimally invasive inlay and underlay tympanoplasty. American Journal of Otolaryngology-Head and Neck Medicine and Surgery 2008;29(6):363-6.

[5] Gamra OB, Mbarek C, Khammassi K, et al. Cartilage graft in type I tympanoplasty: audiological and otological outcome. Eur Arch otorhinolaryngol 2008;265(7):739-42.

[6] Yung M. Cartilage tympanoplasty: literature review. The Journal of Laryyngology \& Otology 2008;122(7):663-72.

[7] England RJ, Strachan DR, Buckley JG. Temporalis fascia grafts shrink. J Laryngol Otol 1997;111(8):707-8.

[8] Primrose WJ, Kerr AG. The anterior marginal perforation. Clin Otolaryngol 1986;11(3):175-6.
[9] Stage J, Bak-Pederson K. Underlay tympanoplasty with the graft lateral to the malleus handle. Clinical otolaryngol 1992;17(1):6-9.

[10] Kartush JM, Michaelides EM, Beeverovski Z, et al. Overunder tympanoplasty. Laryngoscope 2002; 112 (5): 802-7.

[11] Jung TT, Park SK. Mediolateral graft tympanoplasty for anterior or subtotal tympanic membrane perforation. Otolaryngol head and neck surgery 2005;132(4): 532-6.

[12] Farrior JB. Sandwich graft tympanoplasty: experience, results, and complications. Laryngoscope 1989;99(2):213-7

[13] Schraff S, Dash N, Strasnick B. Window shade tympanoplasty for anterior marginal perforations. Laryngoscope 2005;115(9):1655-9.

[14] Nardone M, Sommerville R, Bowman J, et al. Myringoplasty in simple chronic otitis media: critical analysis of long-term results in a 1,000-adult patient series. Otol Neurotol 2012;33(1):48-53.

[15] Gavreil H, Eviatar E. Inferior flap tympanoplasty: a novel technique for anterior perforation closure. BioMed Research International 2013;2013:1-4.

[16] Velepic M, Starcevic R, Ticac R, et al. Cartilage palisade tympanoplasty in children and adults: long term results. International journal of paediatric otolaryngology2012;76(5):663-6. 